\title{
Prolonged follow-up of abnormal visual evoked potentials in multiple sclerosis: Evidence for delayed
}

\section{recovery}

\author{
WB MATTHEWS, MARIAN SMALL \\ From the University Department of Cinical Neurology, The Radcliffe Infirmary, Oxford, UK
}

SUMmaRY A case is described in which the latency of the P100 component of the pattern evoked visual response (VEP) was shown in serial recordings to have remained greatly prolonged for three years after an attack of optic neuritis, but had returned to normal after a further three and a half years. A similar pattern was found in one of a group of 21 patients re-examined between 6 and 8 years after abnormal VEP had been recorded. The pathophysiological implications are briefly discussed.

Persistent prolongation of the pattern evoked visual response (VEP) latency after clinical recovery of retrobulbar neuritis has frequently been reported, ${ }^{12}$ and is indeed the basis for the use of the method in the diagnosis of multiple sclerosis.

A less common finding is the subsequent return of P100 latency to normal which may or may not be paralleled by improvement in visual acuity. ${ }^{3}$ Halliday $e \mathrm{al}^{4}$ in fact suggested that "once present, the increase in latency is unaffected by the recovery process which leads to the restoration of normal amplitude". However, Asselman et al ${ }^{5}$ reported two patients with acute retrobulbar neuritis whose initially delayed VEP returned to normal latency with clinical recovery. Halliday and $\mathrm{McDonald}^{6}$ have recorded this unequivocally in a similar number of cases, one patient showing a return of peak latency to almost within the normal range $(115 \mathrm{~ms}) 2$ years after a clear unilateral delay. Matthews and Small ${ }^{3}$ reported nine instances where the P100 latency returned from abnormal to normal values; in six this was accompanied by improvement in visual acuity.

Whilst these previous studies indicate that P100 does occasionally return to normal, the longest time period reported for recovery to take place is two years. ${ }^{6}$ We have recently examined a patient (MC) in whom the P100 latency was shown to be abnormal three years after an attack of optic neuritis but became normal after a further three and a half years.

Address for reprint requests: Dr Marian Small, The Radcliffe Infirmary, Oxford OX2 6HE, UK.

Received 6 January 1983. Accepted 25 February 1983
This unusual finding prompted a review of patients in whom abnormal VEP had been recorded many years previously, in order to establish whether this delayed recovery was a common phenomenon. A detailed study of this unique case and the results from the follow-up group are given below.

\section{Case 1}

In 1974 , at the age of $27 \mathrm{yr}$ this woman developed right optic neuritis. When seen ten days from the onset the optic disc was swollen and acuity was reduced to perception of hand movements, that in the left eye being 6/4. She had experienced tingling in the toes of the right foot at the same time as the visual loss but this recovered in a few days and there were no signs of disseminated disease. Following a course of tetracosactrin vision improved to $6 / 5$ by six weeks from the onset. In 1976 she had an episode of abnormal sensation in the legs and buttocks but was not seen at this time. When seen in May 1981 she described pain and blurred vision affecting the left eye in October 1980 and since then she had been intermittently aware of misty vision in the eye. Visual acuity was $6 / 5$ in the right eye and $6 / 6$ in the left. The right optic disc was pale but there were no other abnormal signs. Colour vision (Farnsworth-Munsell) was normal in both eyes and no scotomata were detected on a $2 \mathrm{~m}$ tangent screen. In 1981 and again in 1982 she had further episodes of numbness below the waist, with recovery, and later developed paroxysmal itching around the right shoulder.

Her VEP was initially recorded one month after the onset of the attack (fig 1 ), acuity being $R$ : $6 / 9$ and L: 6/5 at the time of testing. The left (normal) eye showed P100 at $100.5 \mathrm{~ms}$ and $16 \mu \mathrm{V}$; the response from the right eye was at $166.8 \mathrm{~ms}$ and $6.3 \mu \mathrm{V}$. In January 1976 , the results were very similar (fig 2), left eye: $100.9 \mathrm{~ms}, 18.3 \mu \mathrm{V}$; right eye: 
$M C$

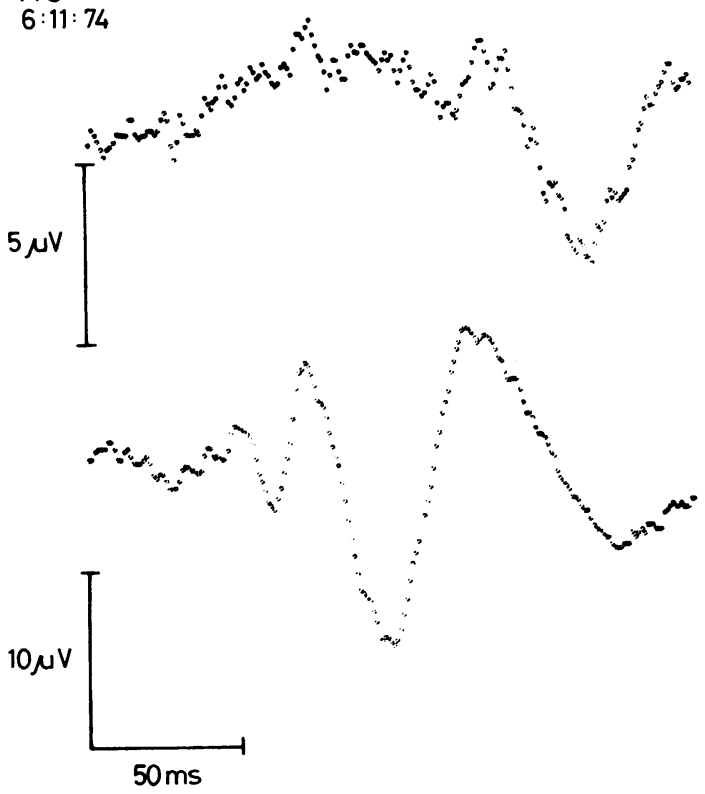

Fig 1 Case 1.VEP one month after the onset of right optic neuritis. Upper trace: right eye $(167 \mathrm{~ms})$; lower trace: left eye $(100 \mathrm{~ms})$.

$\mathrm{MC}$

30:1: 76

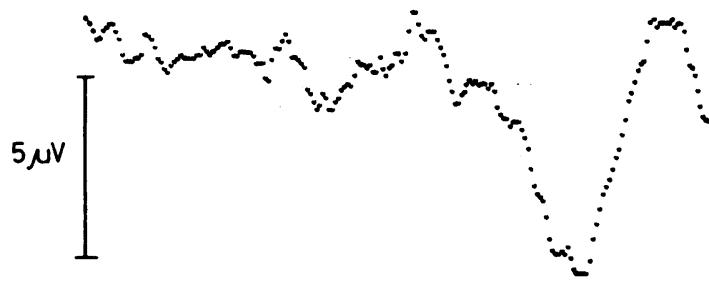

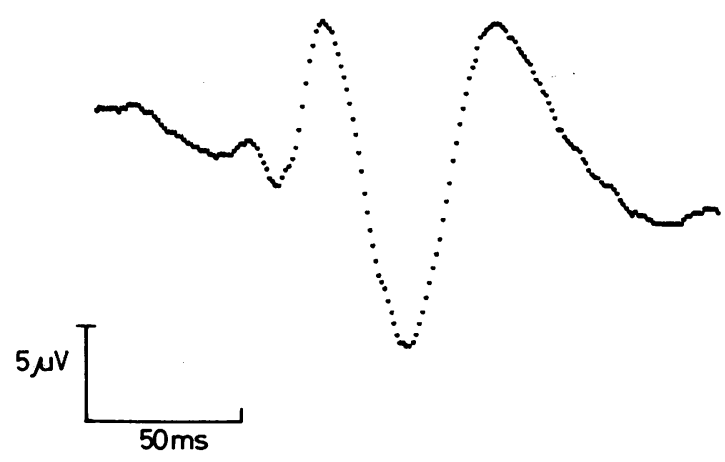

Fig 2 Case 1. VEP.14 months after the first recording. Upper trace: right eye (159 ms); lower trace: left eye (101 ms).
$M C$

$5: 1: 78$
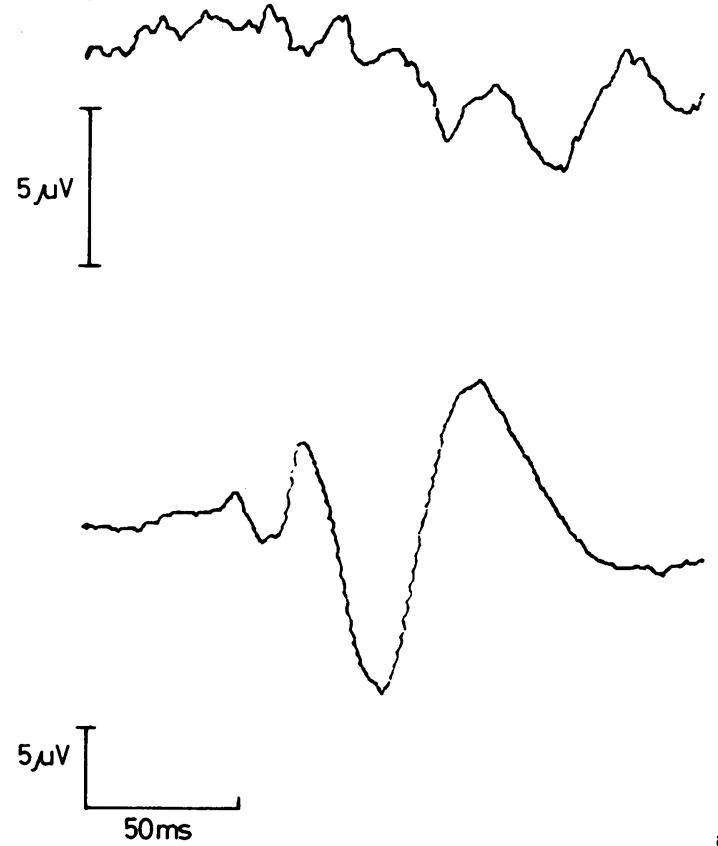

Fig 3 Case 1.VEP 3 years 2 months after the initial test. Upper trace: right eye (156 ms); lower trace: left eye (97 ms).

$158.8 \mathrm{~ms}$ and $7 \cdot 3 \mu \mathrm{V}$. Acuity had improved to $6 / 4$ in both eyes. By January 1978 the amplitude of the response from the right eye was reduced, the latency of the main positive potential being $156.4 \mathrm{~ms}(3.0 \mu \mathrm{V})$, (fig 3$)$. The response from the left eye remained normal at $97.0 \mathrm{~ms}, 16.8 \mu \mathrm{V}$. Visual acuity was $R: 6 / 5$ and $L: 6 / 4$.

VEP was recorded again in June 1981. The right eye (previously abnormal) now showed a normal response, at $103 \mathrm{~ms}$ and $11 \cdot 1 \mu \mathrm{V}$ with a small later peak at $143.9 \mathrm{~ms}$. The left eye (previously normal) showed a late P100 at 155 $\mathrm{ms}, 6.6 \mu \mathrm{V}$. Visual acuity was R: $6 / 5$ and $\mathrm{L}: 6 / 4$ at the time of testing. To check these results the test was repeated in August 1981 with similar findings, (fig 4). Acuity remained unchanged.

Follow-up subjects

Thirty-nine patients who had shown either a bilateral or a unilateral VEP abnormality on initial examination between 1974 and 1976 were written to. Only those who were believed to be mobile and living within reasonable access to the hospital were considered. They were requested to attend for a repeat session and of the original 39, 21 took part in the study. At the time of the initial VEP examination all patients had definite, probable or possible multiple sclerosis. ${ }^{7}$ At follow-up some patients had been reclassified but all were considered to have multiple sclerosis. 

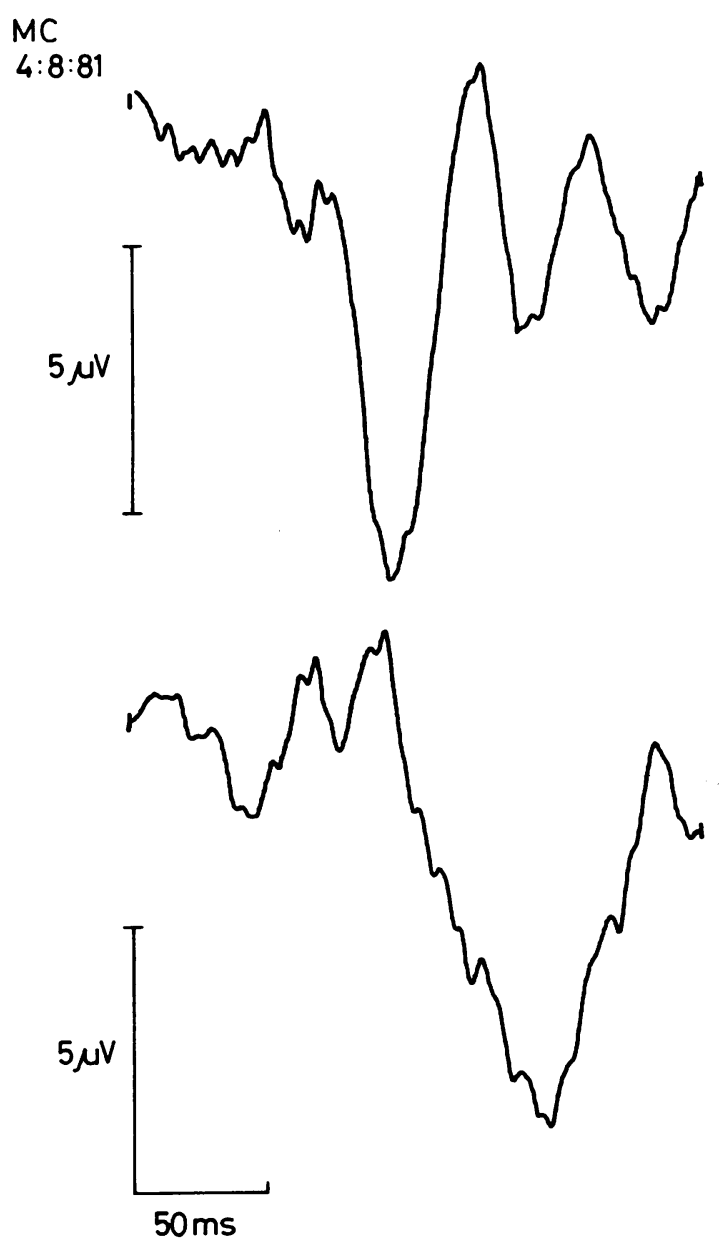

Fig 4 Case 1. VEP 6 years 9 months after the first recording. Upper trace: right eye (94 ms); lower trace: left eye $(148 \mathrm{~ms})$.

\section{Recording}

On both occasions pattern reversal VEPs were recorded for each eye separately by the method described by Matthews $e t$ al. $^{2}$ Although recordings were made from several electrode positions only those from an electrode $5 \mathrm{~cm}$ above the inion to a mid-frontal reference have been considered. Amplitudes of less than $4 \mu \mathrm{V}$ were considered abnormal and the upper limit of normal latency for P100 (mean $+2 \cdot 5 \mathrm{SD})$ was $112 \mathrm{~ms}$.

\section{Results}

\section{FOLLOW-UP GROUP}

Recordings were made from 21 patients, that is 42 eyes. The age range at initial testing was 20-50 years, mean age 34 years, 10 months. The average duration beween the first and follow-up VEP was 6 years 8 months, ranging from 5 years 4 months to 8 years 1 month. At the time of the first VEP, 15 patients showed a bilateral abnormality and six had a unilateral abnormality.

\section{NORMAL EYES}

The mean P100 latency and amplitude of the six normal eyes at the earliest testing was $100.5 \mathrm{~ms}$ and $10.8 \mu \mathrm{V}$ respectively and at follow-up $101.4 \mathrm{~ms}$, $13.1 \mu \mathrm{V}$. In five eyes, the latency remained constant and one eye had moved outside normal limits (from 99 to $128 \mathrm{~ms}$ ) associated with an increase in amplitude but no change in visual acuity. There was no decline in amplitude within this group; three remained the same and three had increased by more than $50 \%$.

\section{ABNORMAL EYES}

Latency was originally abnormal in 26 eyes, mean $134.4 \mathrm{~ms}$, SD $17 \cdot 8$. At follow-up there had been no significant change in the mean; $133.9 \mathrm{~ms}$, SD 24.8 , (Wilcoxon Matched Pairs).

The response from thirteen eyes was originally less than $4 \mu \mathrm{V}$ in amplitude. The mean amplitude at the first VEP of these 13 (disregarding latencies) was $3.3 \mu \mathrm{V}$ (SD 0.59) and on retest was $7.7 \mu \mathrm{V}$ (SD $3.65)$.

In order to form some estimate of individual change over the passage of time, arbitrary figures were chosen. (These were the same as those used in a previous study. ${ }^{3}$ ) A change of $+/-10 \mathrm{~ms}$ in the P100 latency was regarded as significant and for the more labile P100 amplitude the criterion $+/-50 \%$ was adopted.

Individual analysis showed that at the time of initial testing no response could be recorded from five of the total 42 eyes. Visual acuity was however always $6 / 12$ or better. At follow-up there was a response from each of these eyes, ranging in latency from $99.7 \mathrm{~ms}$ to $157.6 \mathrm{~ms}$. Acuity remained unchanged in one, had improved in two and decreased in two: One eye from this group fell within normal limits $(99.7 \mathrm{~ms}, 6 \cdot 1 . \mu \mathrm{V}$ ) accompanied by an improvement in acuity from $6 / 12$ to $6 / 9$.

In all the remaining 31 eyes amplitude either remained the same or increased by more than $50 \%$. No case on retest showed a significant reduction in amplitude except one who showed no response at follow-up and in whom acuity had altered from $6 / 4$ to $6 / 34$. Ten eyes showed an improvement in latency values (that is, a decrease of more than $10 \mathrm{~ms}$ ) as well as a significant increase in amplitude. Of these, acuity improved in five, remained the same in three, was reduced in one and was not recorded in one. Five eyes within this group met the normal criteria 
for $\mathrm{P} 100$ on retest. One patient who had previously shown a bilateral W-shaped waveform (R: 100/119 $\mathrm{ms}$, L: $103 / 121 \mathrm{~ms}$ ) subsequently showed single peaks at R: $97 \mathrm{~ms}$ and L: $100 \mathrm{~ms}$, acuity improving slightly from $6 / 6$ to $6 / 5$ in both eyes. Another patient with previously normal latencies (R: $109 \mathrm{~ms}, \mathrm{~L}: 112$ ms) but with low amplitudes (R: $1.7 \mu \mathrm{V}, \mathrm{L}: 2.9 \mu \mathrm{V}$ ) showed values of $R: 92 \mathrm{~ms}, 8.9 \mu \mathrm{V}$ and $\mathrm{L}: 91 \mathrm{~ms}$, $6.3 \mu \mathrm{V}$ at follow-up. Acuity in the left eye remained constant at $6 / 9$ but had improved in the right eye from $6 / 9$ to $6 / 5$. A subsequently normal P100 was found in only one other patient. He had previously shown a unilateral delay of $144 \mathrm{~ms}(4 \cdot 7 \mu \mathrm{V})$. Improvement in acuity from $6 / 36$ to $6 / 4$ accompanied a decreased latency value of $109 \mathrm{~ms}(10.7$ $\mu \mathrm{V})$ at follow-up.

The responses from three eyes in the improved amplitude group remained constant in latency and in four the latency values increased. In the remaining 13 eyes the amplitude had not significantly altered at retest. Of these, two showed a decreased latency (but not to within normal limits), six had remained the same and in five the latency had increased.

\section{Discussion}

Whilst in the majority of the follow-up cases the P100 latency and amplitude either remained constant or improved (in a few instances to within normal limits), no case showed the same long term improvement associated with normal visual acuity described in Case 1.

One patient who had previously shown bilateral W-shaped waveforms reverted to single P100 peaks with minor improvement only in acuity, but the original unconventional waveform is not necessarily abnormal. In another patient, bilateral abnormally low amplitude responses were subsequently reclassified as normal, but this was based on the amplitude criterion alone. The latency values were less than $112 \mathrm{~ms}$ throughout.

In the two other cases who showed normal VEPs on follow-up, one (with inspection of his early serial recordings) had actually reverted to normal limits within 2 weeks of the original attack of retrobulbar neuritis. The other had also been examined in the intervening period, 1 year after the first recording and his results showed a gradual decrease in P100 latency over time; (1976: $144 \mathrm{~ms}, 1977: 124 \mathrm{~ms}$ and 1982: $109 \mathrm{~ms}$ ). However, his visual acuity was $6 / 36$ initially, improving to $6 / 12$ in 1977 and $6 / 5$ at follow-up. The return of latency to normal paralleled improvement in acuity, unlike case 1, but also provided evidence of a delayed recovery process.

The change described in case 1 therefore does appear to be a rare phenomenon, but nevertheless raises interesting questions of the underlying pathophysiology. It has been generally assumed that the persistent prolongation of the VEP is the result of persistent demyelination, although the restoration of function has remained difficult to explain. ${ }^{6}$ There is little evidence of remyelination in multiple sclerosis and the persistent abnormalities in evoked potentials are not, therefore, unexpected. Our results suggest that, provided no fresh demyelination occurs, a slow healing process may take place. In patients with progressive disease this might well not be detectable, but the opportunity should be taken to re-examine patients in whom abnormal VEPs were recorded soon after the introduction of the technique.

\section{References}

${ }^{1}$ Halliday AM, McDonald WI, Mushin J. Delayed visual evoked response in optic neuritis. Lancet 1972;1:982-5.

${ }^{2}$ Matthews WB, Small DG, Small M, Poutney E. Pattern reversal evoked visual potentials in the diagnosis of multiple sclerosis. J Neurol Neurosurg Psychiatry 1977;40:1009-14.

${ }^{3}$ Matthews WB, Small DG. Serial recording of visual and somatosensory evoked potentials in multiple sclerosis. J Neurol Sci 1979;40:11-21.

${ }^{4}$ Halliday AM, McDonald WI, Mushin J. In: Desmedt JE, ed. Visual evoked potentials in man: new developments. Oxford: Clarendon Press, 1977:438-49.

s Asselman P, Chadwick DW, Marsden CD. Visual evoked responses in the diagnosis and management of patients suspected of multiple sclerosis. Brain 1975;98:261-82.

${ }^{6}$ Halliday AM, McDonald WI. Pathophysiology of demyelinating disease. $\mathrm{Br}$ Med Bull 1977;33:21-7.

${ }^{7}$ McAlpine D, Lumsden CE, Acheson ED. Multiple Sclerosis-A Reappraisal. Edinburgh: Churchill Livingstone, 1972. 